Portland State University

PDXScholar

3-2-2018

\title{
Optimum Suspension Geometry for a Formula SAE
}

Car

Nathan Roner

Portland State University

Follow this and additional works at: https://pdxscholar.library.pdx.edu/honorstheses

Let us know how access to this document benefits you.

\section{Recommended Citation}

Roner, Nathan, "Optimum Suspension Geometry for a Formula SAE Car" (2018). University Honors Theses. Paper 537.

https://doi.org/10.15760/honors.542

This Thesis is brought to you for free and open access. It has been accepted for inclusion in University Honors Theses by an authorized administrator of PDXScholar. Please contact us if we can make this document more accessible: pdxscholar@pdx.edu. 


\title{
OPTIMUM SUSPENSION GEOMETRY FOR A FORMULA SAE CAR
}

\author{
Nathan Roner \\ An undergraduate honors thesis submitted in partial fulfillment of the \\ requirements for the degree of \\ Bachelor of Science \\ in \\ University Honors \\ and \\ Mechanical Engineering
}

Thesis Adviser

Eric Lee

Portland State University

2018 


\section{CONTENTS}

1 Abstract $r$

2 Introduction $\quad 2$

3 Background $r$

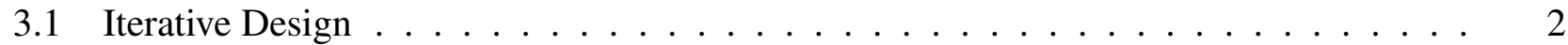

3.2 Formula SAE . . . . . . . . . . . . . . . . . . . . 2

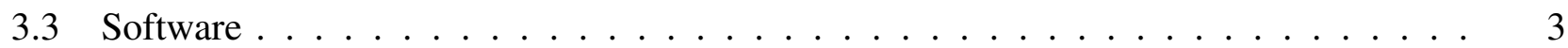

3.4 Definitions of Variables . . . . . . . . . . . . . . . . . . 3

4 Methods $\quad 4$

4.1 Known Requirements . . . . . . . . . . . . . . . . . . . . . . . . . . 4

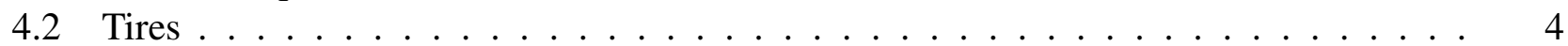

4.3 Team Data . . . . . . . . . . . . . . . . . . . . . . . 4

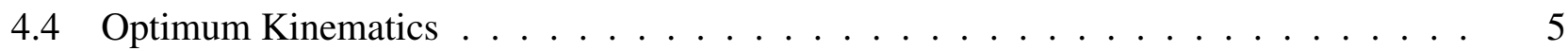

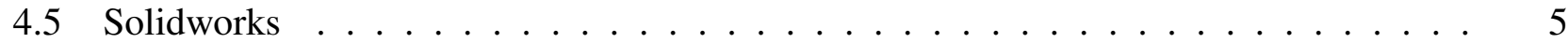

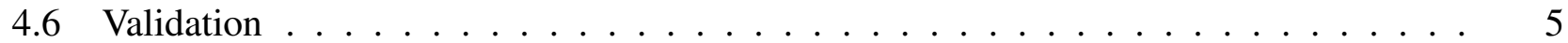

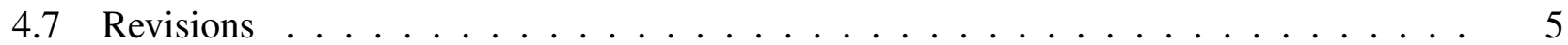

5 Design $\quad 6$

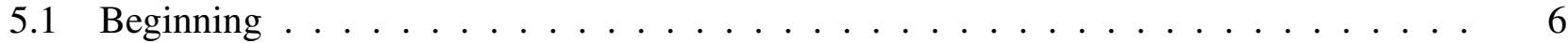

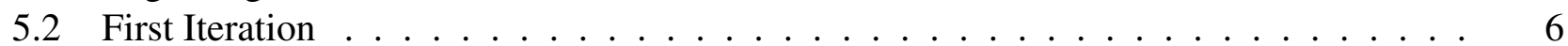

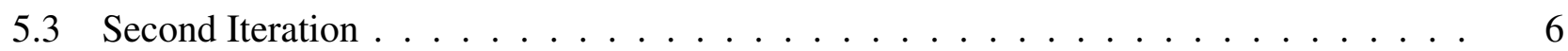

5.4 Third Iteration $\ldots \ldots \ldots \ldots \ldots \ldots \ldots$

5.5 Subsequent Iterations . . . . . . . . . . . . . . . . . . 7 


\section{Abstract}

This paper will explore the features that optimize suspension performance for a Formula SAE racecar, focusing on suspension geometry. Employing research and designs from previous year's cars, the suspension will be designed using the iterative design process. To help with this process, multiple programs and methods will be used. When the design is finalized it will be built and installed on the 2019 Viking Motorsport's Formula SAE car.

\section{Introduction}

The suspension is arguably the most important part of a vehicle, this is especialy true for a racecar. Without a good suspension design the performance of a racecar will suffer dramatically [1]. From reduced cornering capability to decreased acceleration and braking performance [2]. The suspension can make the difference between winning a race or crashing at the first corner. The suspension of a vehicle is the combination of multiple parameters that influence each other, the most prominent are defined in Section 3.4 [3]. The overall design and implementation of racecar suspension has not changed dramatically in the past decade $[1,4,5]$. Due to the multitude of factors to consider in the design of a suspension there are always compromises that must be made. This provides the opportunity for creative ways to optimize the design. This paper focuses on the key geometric parameters that affect the suspension design for a Formula SAE racecar.

\section{Background}

\subsection{Iterative Design}

Due to the number of parameters affecting performance, suspension design is a perfect example of iterative design. Iterative design in the repeating process of designing, testing, analyzing and refining [6]. The first step in the process is to define the requirements that the current iteration must meet. Then a design is completed that meets the stated requirements [6]. After the design is finished, it is tested to see how well it meets the stated requirements [6]. The results are then analyzed, and the requirements are changed if needed [6]. This cycle repeats until either the allotted time is exhausted or another factor such as budget has been reached [6]. The entire process, as well as pre and post process, is shown in Figure 1.

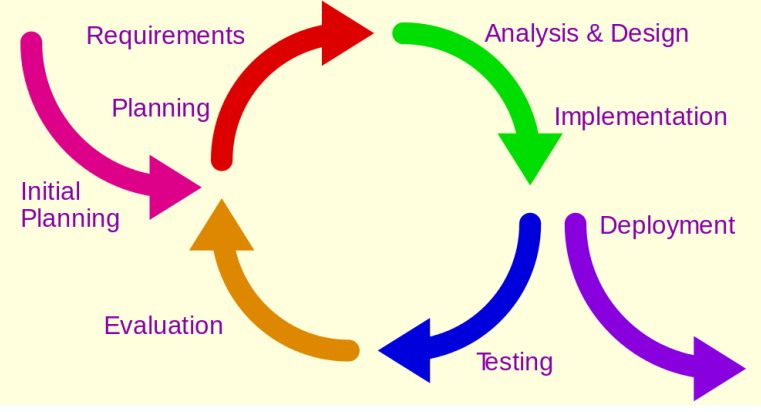

Fig. 1. Diagram of the iterative design process [6]

Without iterative design the process of suspension design would be next to impossible [7]. To see what each key parameter changes there would be a large amount of assumptions and complex geometric equations that would be oversimplifications of the system [3]. Due to the complex and unsolvable nature of the geometry, significant errors would arise that affect the performance of the final design.

\subsection{Formula SAE}

Formula SAE (FSAE) is an international collegiate competition in which student teams design, build, and compete with a car built from scratch [8]. There are two different classes that teams can enter in, one being an internal combustion powered vehicle and the other being an electrical powered vehicle. There are currently two competitions per year in the US - one in Michigan and the other in Nebraska. At each competition there are approximately 120 teams from around the world that compete. The FSAE team that represents Portland State University is Viking Motorsports (VMS) [9]. They are currently designing an electric vehicle that will compete in the 2019 Nebraska competition. An example of an FSAE vehicle is the 2017 VMS racecar that is shown in Figure 2. 


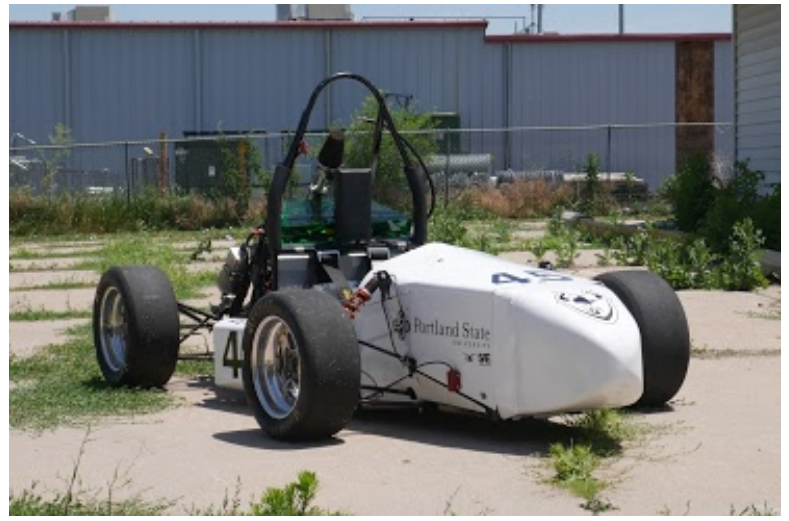

Fig. 2. A picture of the 2017 Viking Motorsport's internal combustion FSAE car.

\subsection{Software}

The anyalysis in this paper will be heavily reliant on multiple pieces of software. The primary software used is Optimum Kinematics, a geometric modeling software that specializes in automotive suspension design [10]. Optimum Kinematics will be used for creating the bulk of the suspension design. The second piece of software is Solidworks which is the industry standard for computer aided design [11]. Solidworks will be used to model the suspension with the rest of the vehicle to see how they interact. The last piece of software used is Microsoft Excel [12]. Excel will be used to simplify calculations handling and to help reduce calculation errors.

\subsection{Definitions of Variables}

The following are the most common variables used when designing a suspension $[1,5,13]$.

A-arm

Attaches the upright to the chassis

Camber

Angle of the tires shown in Figure 3

Contact Patch The area of the tire that contacts the pavement

Caster

Angle of the tires shown in Figure 3

Drivability The ability for the driver to control the vehicle
Instantaneous imaginary point used to conCenter (IC) struct the roll center.

Slip Angle The angle between where the tire is pointing and where the tire is traveling

Steering Force The force required for the drive to turn the steering wheel.

Steering

Geometry

The geometry that influences the steering force.

Suspension

Geometry

Comprised of the A-arm geometry and the upright.

Suspension

Points

The end points of the A-arms.

Track width

The distance between the centers of the tires.

Tire Forces There are two force components, one being the longitudinal force that acts in line with the car, and the other being the lateral force which acts perpendicular to the car.

Upright Vertical component that houses the wheel bearing.

Wheelbase The distance between the axles.

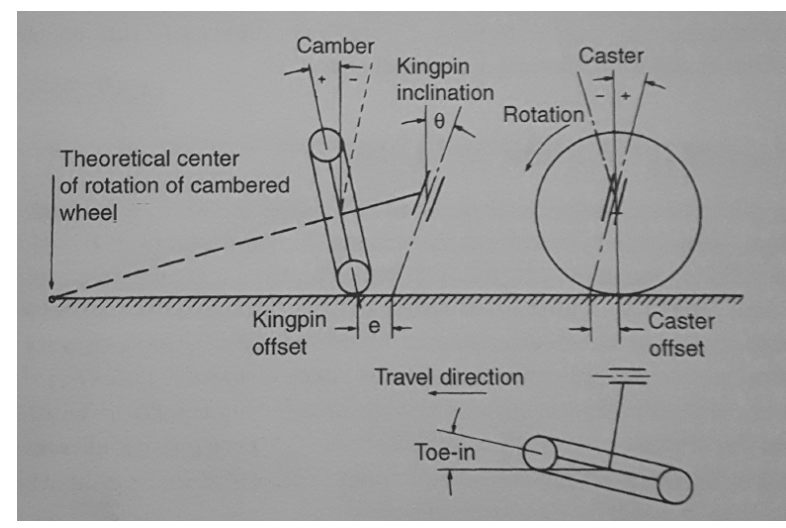

Fig. 3. Diagram of the major variables of a suspension [5]. 


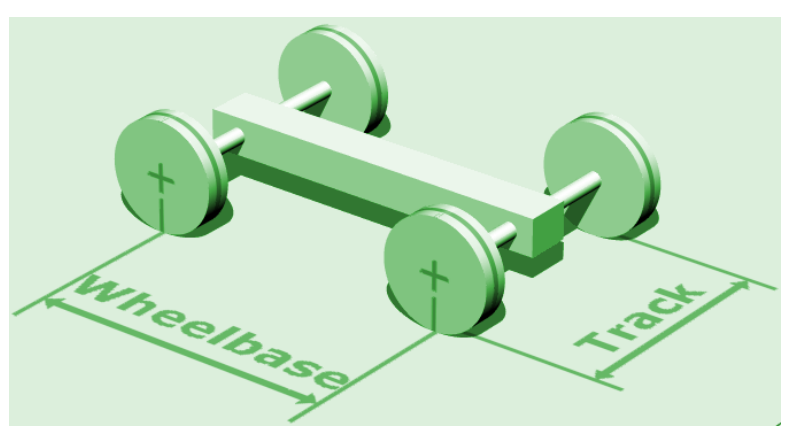

Fig. 4. Image showing the wheelbase and track width parameters [14].

\section{Methods}

This paper outlines a series of steps used to plan, design, and validate the suspension design. The initial iteration is based off known requirements set forth by the Viking Motorsports team [9]. Subsequent iterations include both tire data and team information that is provided by the Viking Motorsports team. Each iteration is designed using a combination of Optimum Kinematics and Solidworks. Once an iteration was complete it underwent validation to set requirements for the next iteration. This was continued until the design halt deadline. This thesis will focus on the initial three iterations and talk about the next steps involved with completing the design.

\subsection{Known Requirements}

Initially there are only two parameters that have specified values. The first requirenment is the track width must be 60 " so the car can fit out the shop door [9]. This results in two possible track widths depending of the width of the tires, one being 54" with 6" tires and the other being 53" with 7" tires. The second parameter is the wheelbase which must be a minimum of 60 " based on FSAE rule T2.3 [15]. To maximize the turning radius and other handling characteristics the smaller the wheelbase the more optimum the performace will be, so 60 " will be the design wheelbase [16].

\subsection{Tires}

Tires are the prominent part of a vehicle's suspension they provide the forces that allow the vehicle to accelerate as well as corner [17]. Poorly optimized tire performance can significantly reduce the speed that the vehicle is able to operate at under all conditions. The primary way to design a suspension to take advantage of the tire is to model the tires off empirical data [18]. The data to be used is provided by the FSAE Tire Test Consortium and has been fitted with a model based off the Pacejka 2006 tire equations [17, 19]. Using the model of the tires, a series of graphs are produced that are vital to the optimization of the tires [18]. The graphs are used to optimize the following parameters: camber, steering force, steering geometry, camber recovery, coefficients of friction, lateral forces, and slip angles [5]. One example of these graphs is shown in Figure 5. This data will be used in all iterations following iteration one and will be the main justification for all design deci-

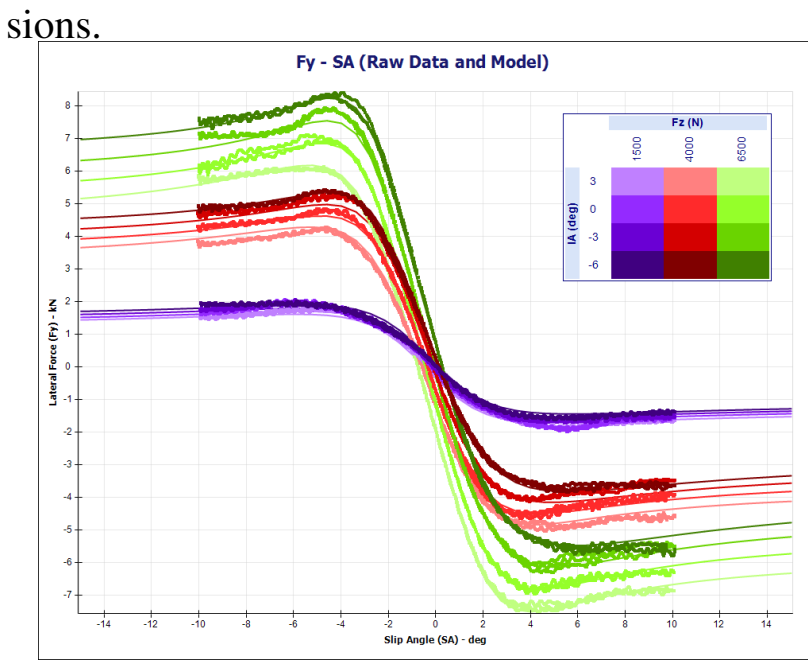

Fig. 5. Figure showing the lateral force vs slip angle of the tires that will be used on the 2019 VMS car. $[9,18]$

\subsection{Team Data}

VMS provided two datasets: steering force data and the suspension designs from previous cars [9]. The steering force data will be used to determine steering geometry to insure the drivability of the car [3]. The data show that the optimum steering force is $3 \mathrm{ft}-\mathrm{lb}$ acting on the steering wheel [9]. The previous suspension designs will allow quick advancement in the design since it is possible to see what has worked in the past and what has not. These 2 datasets are important to insure the design is as optimized as possible while being usable by VMS. 


\subsection{Optimum Kinematics}

Optimum Kinematics is the primary software that will be used to facilitate the design of the suspension. The software calculates the kinematic relations of the suspension and generates graphs of the results [10]. These graphs are used to make slight changes of the individual components and see their effects on the overall design. One example of a generated plot is shown in Figure 6. The software also allows ease of iterations since it supports have multiple designs at once and the ability to quickly switch between them. Optimum Kinematics has an iterative design feature automatically steps though different suspension point locations and plot the results for analysis [10].

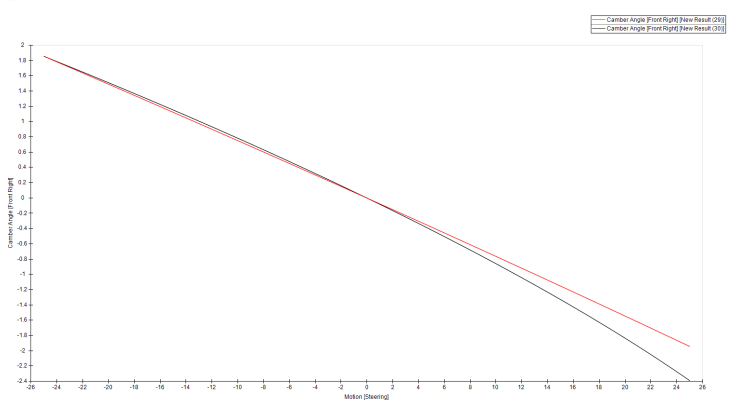

Fig. 6. An example of the type of plot that is generated by Optimum Kinematics [10].

\subsection{Solidworks}

Solidworks will be used in three significant ways for this paper. One way that it is used is to help visualize specific relations between different geometry components. An example of this is seeing how changing components effects instantaneous center which is shown in Figure 7 . It will also be used to visualize the positioning of major components in relation to the chassis design shown in Figure 8. The third significant use of Solidworks is to allow easy distribution of the design to insure quick and effective validation.

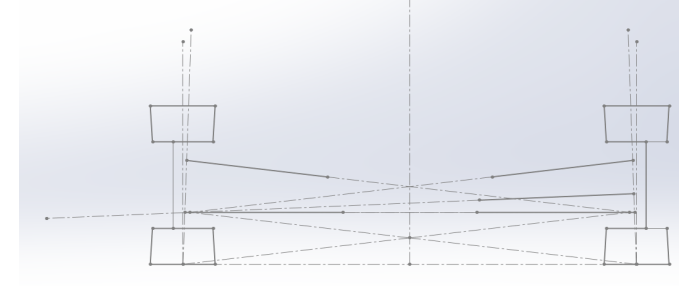

Fig. 7. Solidworks sketch that is used to determine the instantaneous center for a given suspension geometry.

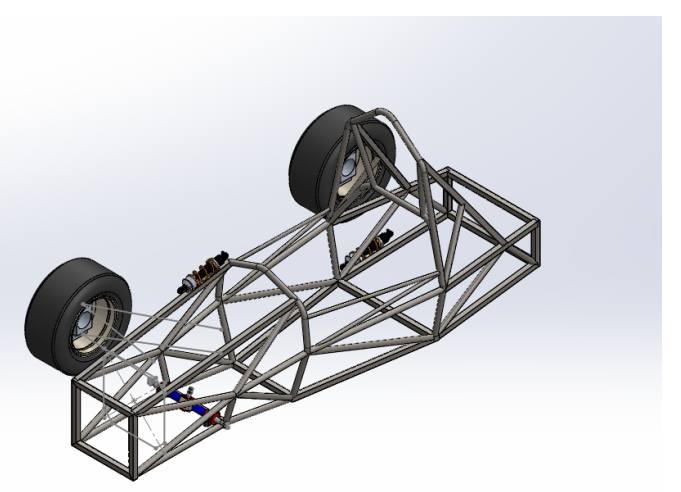

Fig. 8. Solidworks assembly showing the tires that will be used and how they relate to the current chassis design [9].

\subsection{Validation}

The geometry will be validated with respect to the chassis after every major revision. During a Viking Motorsports team meeting the design is validated withe the other systems so problems can be spotted. If a problem is found a plan is made to fix the issues in a timely manner [9]. New design parameters will also be brought up during these meetings to make sure that the suspension design will work with the rest of the vehicle. This will help ensure effective congruent design of both the suspension and the chassis.

\subsection{Revisions}

Following the iterative design process, it is critical to create an optimized suspension design. Since there are a significant number of parameters that are not possible to outright solve for, compromises must be made. This leads to major revisions 
as well as minor revisions. Major revision for the purpose of the paper are whenever new parameters are introduced into the design these will be labeled as $\operatorname{Rev} x$ where $x$ is the major iteration. Minor revisions are for smaller changes that create a noticeable visual change in the design they will be labeled as Rev 1.x where $\mathrm{x}$ is the current minor revision. The iterations will continue until there is no more time left since there is no acceptable final design for any suspension design.

\section{Design}

\subsection{Beginning}

The beginning of the design process was spent creating supporting tools to enable easy validation of the design. Most of these tools were drawings created in Solidworks to help show how different geometry shapes affect the suspension parameters. There were also a few tools created in excel to calculate the parameters that have known equations. One example of this is a spreadsheet that was created to calculate the normal forces on each wheel while the vehicle was under different driving conditions. Once all the tools where created the iterative design process was started.

\subsection{First Iteration}

The first iteration of the suspension design is shown in Figure 9. The main purpose of this iteration was to get used to the software and create an initial starting point. The only parameters that were taken into consideration were the track width and wheelbase. This resulted in a poor design, but a good starting point to quickly see advancement.

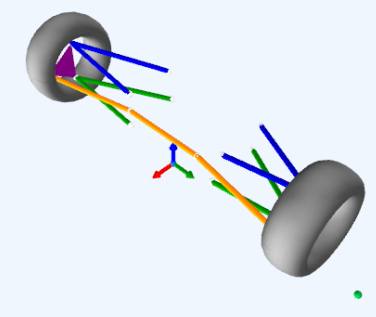

Fig. 9. Iteration 1 of the suspension design as viewed from Optimum Kinematics.

\subsection{Second Iteration}

The second iteration is shown in Figure 10. This is the first iteration where other parameters besides the track width and wheelbase were considered. The new parameters in this iteration were how the design integrated with the chassis design, turning radius, and the correct tire size. This resulted in a better suspension design, but there were still some significant issues that needed to be fixed. One of the biggest issues was that the design of the chassis was undergoing major revisions that affect the suspension points.

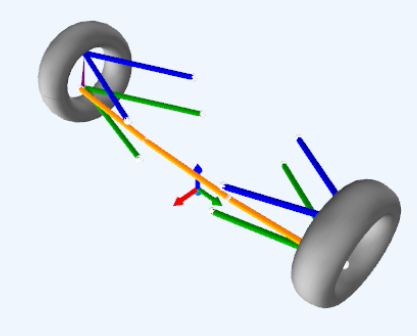

Fig. 10. Iteration 2 of the suspension design as viewed from Optimum Kinematics.

\subsection{Third Iteration}

The third iteration is shown in Figure 11. This iteration had the biggest number of new parameters incorporated into the design. These included the tire data and steering force data. The tire data was used to find the optimum camber angles, steering angle relations, and relating steering force data to the geometry [19]. This resulted in the first usable suspension design, although there is still some more work that could be done to create a more optimized design. One example of an improvement that could be made is that the drivetrain of the car is still not complete, so the rear suspension is not yet applicable to the overall design. 


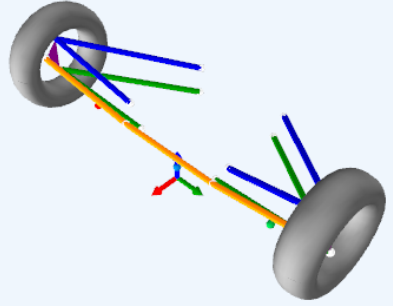

Fig. 11. Iteration 3 of the suspension design as viewed from Optimum Kinematics.

\subsection{Subsequent Iterations}

After the third iteration the progress slowed down due to diminishing returns. Additional iterations have yielded less dramatic improvement in the performance of the suspension. Further iterations will continue to be created until the design halt deadline. During these iterations the steps taken in this paper will continue to be used. The final suspension design will be featured on the 2017 Viking Motorsports FSAE car.

\section{References}

[1] Bastow, D., Howard, G., and Whitehead, J. P., 2004. Car suspension and handling. Society of automotive engineers.

[2] Staniforth, A., 2009. Competition car suspension: design, construction, tuning. Haynes Publ.

[3] Dixon, J. C., 1996. Tires, suspension, and handling. SAE International.

[4] Gaffney, E. F., and Sallnas, A. R. "Introduction to formula sae suspension and frame design". PhD thesis, University of Missouri.

[5] Milliken, W. F., Kasprzak, E. M., Milliken, D. L., and Metz, L. D., 1995. Race car vehicle dynamics. SAE International.

[6] The Interaction Design Foundation, 2017. Design iteration brings powerful results. so, do it again designer!, Mar.
[7] Moore, L., 2014. Importance of suspension and wheel alignment, Oct.

[8] SAE International, 2018. Student events.

[9] Viking Motorsports, 2018. Our cars.

[10] OptimumG. Optimumkinematics.

[11] Dassault Systmes. Solidworks.

[12] Microsoft. Excel.

[13] , 1978. Vehicle dynamics terminology. Society of Automotive Engineers.

[14] Contributors, W., 2018. Wheelbase wikipedia, the free encyclopedia.

[15] Society of Automotive Engineers, 2016. Formula sae rules, Sep.

[16] "The effects of wheelbase and track on vehicle dynamics". Society for Technical Communication.

[17] Pacejka, H., 2006. Tyre and Vehicle Dynamics. Elsevier Science \& Technology Books.

[18] OptimumG. Optimumtire.

[19] Calspan Corporation \& Formula SAE Tire Test Consortium, 2015. Fsae tire data. 